\title{
ANALISA BIAYA OPERASIONAL KENDARAAN BUS ANGKUTAN KOTA JURUSAN PALANGKA RAYA-PANGKALAN BUN
}

\author{
Muhammad Gemilang P.U. ${ }^{1}$, Nirwana Puspasari ${ }^{2}$ \\ Program Studi Teknik Sipil Universitas Muhammadiyah Palangka Raya \\ ²nirwana.puspasari@yahoo.com
}

\begin{abstract}
ABSTRAK
Transportasi merupakan peranan yang penting pada aspek kegiatan ekonomi sosial dan budaya. Dilihat dari distribusi keluar masuknya arus penumpang transportasi darat armada Bus jurusan Palangkaraya-Pangkalan Bun merupakan jasa Transportasi yang paling diminati sebab waktu tempuh lebih cepat dan efisien. Tujuan penelitian yakni untuk mengetahui besarnya biaya operasional kendaraan angkutan umum bus Palangka RayaPangkalan Bun. Metode pengumpulan data penumpang dan data armada bus adalah metode penetuan sampel tak acak (non random sampling). Data primer berupa biaya operasional kendaraan dianalisis dengan metode pendekatan biaya per kilometer untuk setiap kendaraan, pendapatan dianalisis dengan metode pendekatan jumlah pendapatan rata-rata perusahaan per tahun dan dikurang dengan total biaya operasional kendaraan per kilometer, tarif dianalisis dengan metode menjumlahkan komponen biaya tetap, biaya tidak tetap dan biaya overhead dalam satuan per penumpang dan Fare Box Ratio (FBR) dianalisis dengan metode perbandingan nilai biaya operasional kendaraan pertahun dengan pendapatan pertahun. Dari hasil penelitian diperoleh besarnya kebutuhan Biaya Operasional yang di keluarkan sebesar $81 \%$ dari Pendapatan pertahun. Dengan perhitungan Factor Load sebesar 12 penumpang per Trip selama tiga tahun terakhir. Tarif yang dikeluarkan untuk pembelian tiket per satu kali keberangkatan adalah Rp. 130.000,00 dengan nilai Fare Box Ratio (FBR) sebesar $123 \%$ sehingga dapat dikategorikan mendapat keuntungan.
\end{abstract}

Kata Kunci : biaya operasional kendaraan, bus damri, palangka raya-pangkalan bun.

\section{ABSTRACT}

Transportation is an important role in aspects of social economic and cultural activities. Based on the distribution of passenger traffic in and out of the land transportation, the Bus fleet majoring in PalangkarayaPangkalan Bun is the most desirable transportation service because travel times are faster and more efficient. The research objective is to determine the magnitude of operational costs for public transportation vehicles Palangka Raya-Pangkalan Bun. The method of collecting passenger data and bus fleet data is a non-random sampling method. Primary data in the form of vehicle operating costs are analyzed by the method of cost per kilometer approach for each vehicle, revenue is analyzed by the method of approaching the average amount of revenue of the company per year and subtracted by total vehicle operating costs per kilometer, rates are analyzed by the method of adding the fixed cost components, costs variable and overhead costs in units per passenger and Fare Box Ratio (FBR) are analyzed using the method of comparing the value of Vehicle Operating Costs per year with annual income. From the results of the study, the amount of Operational Cost needs is spent at $81 \%$ of annual income. With a Factor Load calculation of 12 passengers per Trip over the past three years. The fare incurred for ticket purchase per one time departure is Rp 130,000.00 with a Fare Box Ratio (FBR) of $123 \%$ so that it can be categorized as a profit.

Keywords: damri bus, palangka raya-pangkalan bun, vehicle operating costs. 


\section{PENDAHULUAN}

\section{Latar Belakang}

Dalam mendukung proses transportasi angkutan umum khususnya di Indonesia perlu memperhatikan komponen-komponen pendukungnya, yaitu orang atau barang yang diangkut, sarana dan prasarana serta sistem operasionalnya agar terselenggara transportasi yang efektif dan efisien. Seiring pertambahan waktu dan perkembangan kota serta aktivitas manusia terjadi suatu perubahan ditandai dengan fluktuasi pertumbuhan jumlah penduduk, pemilikan kendaraan, pendapatan, tenaga kerja, dan pola perilaku serta tren masyarakat dalam bertansportasi. Sejalan dengan hal tersebut, maka akan terjadi perubahan permintaan akan kebutuhan transportasi, sehingga perlu peningkatan sarana dan prasarana serta perbaikan manajemen transportasi untuk mewujudkan sistem transportasi yang lebih baik di masa mendatang.

Angkutan kota sebagai bagian dari sistem transportasi perkotaan merupakan salah satu kebutuhan pokok masyarakat dan merupakan bagian yang tidak dapat dipisahkan dengan kehidupan kota. pada umumnya keberadaan angkutan kota sangat dibutuhkan tetapi apabila tidak ditangani secara baik dan benar maka merupakan masalah bagi kehidupan kita. Ditinjau dari sistem transportasi kota, angkutan umum merupakan bagian yang sangat penting dari sistem transportasi kota dan merupakan komponen yang tak terpisahkan.

Sejak terbukanya jalur transportasi darat yang menghubungkan antar kota yang ada di Provinsi Kalimantan Tengah menjadi salah satu ladang usaha bagi para pemilik modal untuk membuka usaha dibidang jasa angkutan darat. Secara nyata kita dapat menilai keadaan atau kondisi sistem angkutan yang buruk akan menyebabkan turunnya mutu pelayanan dan sistem transportasi kota secara keseluruhan bagi pengelola, kondisi angkutan umum yang pengoperasiannya kurang baik akan merugikan terutama ditinjau dari segi finansial karena biaya operasi kendaraan secara keseluruhan akan meningkat sedangkan pendapatan cenderung tidak berubah. Justru dalam banyak hal akan turun akibat banyaknya pengguna angkutan umum meninggalkan transportasi bus untuk selanjutnya menggunakan kendaraan lain bagi pemenuhan kebutuhan mobilitasnya.

Perusahaan Otobus (PO) Damri yang berada di jalan Tjilik Riwut Km 7 Kota Palangka Raya Provinsi Kalimantan Tengah merupakan objek dari penelitian yang akan dilaksanakan. Hal ini dijadikan objek berdasarkan pengamatan karena Damri adalah salah satu perusahaan yang bergerak dibidang jasa angkutan orang dan barang.

Perusahaan otobus Damri melayani jurusan Palangka Raya-Pangkalan Bun. Berdasarkan dari uraian diatas maka penelitian ini bertujuan untuk mengetahui dan menganalisa Perhitungan Biaya Operasional Kendaraan (BOK).

\section{a. Rumusan Masalah}

Berdasarkan latar belakang yang telah ada, dapat dirumuskan suatu pokok permasalahan yang akan dibahas adalah sebagai berikut:

1. Seberapa besar biaya operasional rata-rata yang dikeluarkan dalam satu kali keberangkatan?

2. Berapa jumlah penumpang rata-rata yang diangkut dalam satu kali keberangkatan?

3. Berapa besaran biaya pendapatan dari hasil penjualan tiket per satu bulan serta Fare Box Ratio (FBR)?

4. Berapa tarif penumpang angkutan umum bus yang beroperasi pada jurusan Palangka Raya Pangkalan Bun?

b. Tujuan Penelitian

Adapun tujuan yang diharapkan dari hasil penelitian ini adalah sebagai berikut:

1. Untuk mengetahui besarnya biaya operasional kendaraan angkutan umum bus.

2. Untuk mengetahui jumlah penumpang rata-rata yang diangkut dalam satu kali keberangkatan.

3. Untuk mengetahui dan menganalisa besaran biaya pendapatan dari hasil penjualan tiket per satu bulan serta Fare Box Ratio (FBR).

4. Untuk mengetahui besaran tarif penumpang bus yang beroperasi pada jurusan Palangka RayaPangkalan Bun.

\section{c. Batasan Masalah}

Untuk menghindiri penelitian yang meluas serta untuk memberikan arah yang jelas dan memudahkan penyelesaian permasalahan di atas agar tercapainya tujuan maka perlu adanya pembatasan permasalahan yaitu sebagai berikut:

1. Lokasi penelitian yang ditinjau adalah rute angkutan umum bus Perusahaan Otobus (PO) 
2. Damri yang berada di jalan Tjilik Riwut $\mathrm{Km} 7$ kota Palangka Raya.

3. Hari operasi diwakili oleh Tujuh hari setiap rute yaitu hari senin sampai dengan hari minggu.

4. Data penumpang yang digunakan adalah data penumpang yang naik dan turun dari terminal Damri yang berada di jalan Tjilik Riwut Km 7 kota Palangka Raya.

d. Manfaat Penelitian Manfaat dari penelitian ini adalah:

1. Dapat secara langsung mengetahui pengelolaan operasional otobus dalam peningkatan mutu pelayanan terhadap pengguna angkutan ini.

2. Dapat digunakan sebagai referensi untuk menentukan besarnya nilai tarif yang diberlakukan.

3. Untuk menambah wawasan dan pengetahuan dibidang transportasi darat yang beroperasi terkhusus di kota Palangka Raya Provinsi Kalimantan Tengah.

\section{TINJAUAN PUSTAKA}

\section{Biaya Operasional Kendaraan}

Biaya operasional kendaraan (BOK) adalah suatu lintasan penghasilan untuk keperluan kendaraan dalam perjalanan. Komponen biaya operasional kendaraan ini terdiri dari:

1. Biaya tetap (Standing Coast)

2. Biaya tidak tetap (Running Cost)

3. Biaya Overhead

a. Biaya Tetap (Standing Cost)

Biaya tetap adalah biaya yang dalam pengeluarannya tetap tanpa tergantung pada volume produksi yang terjadi. Biaya tetap ini dapat dikelompokkan sebagai berikut:

1. Biaya modal kendaraan (BM)

2. Biaya penyusutan (BP)

3. Biaya perijinan dan administrasi (BPA)

4. Biaya asuransi (BA)Adalah biaya asuransi kecelakaanyang dibayarkan kepada suatuperusahaan asuransi.

b. Biaya Tidak Tetap (Running Cost) Biaya Tidak Tetap (Running Cost) Biaya tidak tetap merupakan biaya yang dikeluarkan pada saat kendaraan beroperasi. Komponen biaya yang termasuk ke dalam biaya tidak tetap iniadalah:

1. Biaya Bahan Bakar (BBM)
2. Biaya Pemakaian Ban ( PB )

3. Biaya Perawatan dan PerbaikanKendaraan ( $\mathrm{PP}$ )

4. Biaya Pendapatan Sopir ( PS )

5. Biaya Retribusi Terminal ( BR )

c. Biaya Overhead

Biaya overhead adalah biaya yang secara tidak langsung dikeluarkan oleh pemilik kendaraan atau pengusaha angkutan penumpang yang akandipergunakan untuk keperluan biaya operasional kendaraan, dan biaya keperluan kantor lainnya

d. Tarif

merupakan jumlah biaya yang harus dibayar oleh penumpang serta besarnya pemasukan perusahaan angkutan.

\section{METODE PENELITIAN}

a. Lokasi Penelitian

Ada beberapa perusahaan bus di kota Palangkaraya yang melayani kebutuhan angkutan antar kota maupun angkutan antar Provinsi, akan tetapi dalam penelitian ini hanya mengambil 1 perusahaan sebagai objek penelitian Biaya Operasional Kendaraan angkutan bus, khususnya jurusan Palangka Raya-Pangkalanbun, yaitu perusahaan Otobus Damri yang beralamat di jalan Tjilik Riwut KM. 7 Kota Palangka Raya Kalimantan Tengah.

b. Tahapan Penelitian

Agar proses penelitian bisa berjalan dengan baik dan terarah, maka perlu tahapan yang sistematis yaitu:

1. Menentukan objek penelitian

2. Melakukan studi pustaka, yaitu mempelajari beberapa penelitian terdahulu yang serupa agar lebih memahami maksud dan tujuan dari peneltian tersebut.

3. Mengumpulkan beberapa data, seperti:

a. Data primer

b. Data sekunder

4. Mengolah dan menganalisa data, yaitu menghitung dan menganalisa:

a. Besarnya biaya operasional kendaraan ratarata yang dikeluarkan perusahaan setiap tahun.

b. Jumlah penumpang rata-rata yang dilayani setiap tahun. 
c. Besaran biaya pendapatan rata-rata dari hasil penjualan tiket selama setahun.

d. Tarif yang ideal bagi penumpang bus jurusan Palangka Raya- Pangkalanbun.

5. Kesimpulan

6. Selesai

c. Bagan Alir Penelitian

Tahapan penelitian ini juga dapat disajikan dalam bentuk bagan alir sebagai berikut ini:

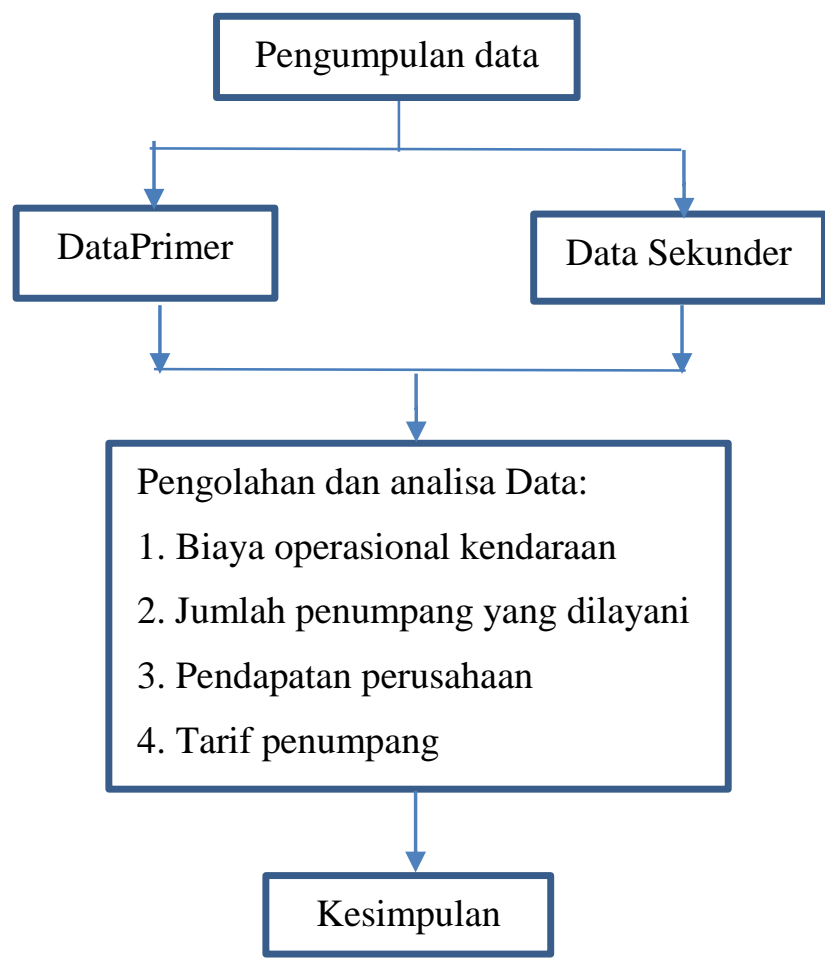

Gambar 1 Bagan Alur Penelitian

d. Metode Pengumpulan Data

Dalam Warta (2006). Metode pengumpulan data yang dilakukan dalam penelitian ini adalah metode penetuan sampel tak acak (non random sampling). Adapun yang dimaksud dengan metode ini adalah suatu cara pengumpulan data yang sifatnya tidak menyeluruh, artinya hanya sebagian saja dari populasi yaitu hanya mencakup sampel yang memenuhi syarat atau pertimbangan tertentu.

e. Data Primer

Data yang diperoleh dengan cara melakukan survey dilapangan. Data primer yang dibutuhkan meliputi data sebagai berikut :

1. Data biaya operasi kendaraan.

2. Data asal tujuan perjalanan penumpang Data tersebut diperoleh melalui

a. Observasi lapangan yaitu pengamatan langsung terhadap objekdilapangan. b. Kuisioner yaitu pertanyaan yang akan diisi oleh pihak PO Bus.

c. Interview yaitu melakukan wawancara dengan pihak yang menjadi objek penelitian, dalam hal ini adalah PO Damri.

d. Kepustakaan yaitu mempelajari dan mengutip dari bahan buku pendukung sebagai bahan acuan penulisan.

f. Data Sekunder

Data yang didapat dari sumber publikasi pemerintah diantaranya Dinas Perhubungan, DDLAJ serta instansi terkait lainnya.

a. Tarif yang berlaku pada daerah kajian.

b. Jumlah trayek yang beroperasi pada daerah kajian.

c. Kuisioner penumpang

g. Analisis Data

Dari hasil data primer dan sekunder kemudian di adakan analisa untuk dapat mengetahui:

a. Tarif yang berlaku pada daerah kajian.

b. Jumlah trayek yang beroperasi pada daerah kajian.

c. Kuisioner penumpang

h. Analisis Data

Dari hasil data primer dan sekunder kemudian di adakan analisa untuk dapat mengetahui:

1. Seberapa besar biaya operasional rata-rata yang dikeluarkan dalam satu kali keberangkatan?

2. Berapa jumlah penumpang rata-rata yang diangkut dalam satu kali keberangkatan?

3. Berapa besaran biaya pendapatan dari hasil penjualan tiket per satu bulan serta Fare Box Ratio (FBR)?

4. Berapa tarif penumpang angkutan umum bus yang beroperasi pada jurusan Palangka Raya - Pangkalan Bun?

i. Perhitungan yang di gunakan Biaya Operasional Kendaraan (BOK)

Dalam Wulandari, (2016). Berdasarkan penggolongan biaya, maka susunan perhitungan biaya pokok jasa angkutan jalan raya adalah sebagai berikut:

1. Perhitungan Biaya Tetap

Komponen-komponen biaya tetap yang dihitung adalah sebagai berikut:

a. Bunga modal

b. Biaya penyusutan

c. Biaya pengelolaan : Biaya ini terdiri dari biaya pengelolaan armada, biaya kantor, 
d. administrasi, listrik, air, telpon, pajak perusahaan.

e. Biaya STNK

Perpanjangan STNK dilakukan setiap tahun sekali dan biayanya sesuai dengan peraturan yang berlaku.

f. Biaya KIR

KIR kendaraan dilakukan sekali setiap 6 bulan.

g. Gaji Supir

Penghasilan sopir kendaraan berupa gaji, dan tunjangan sosial.

h. Gaji karyawan

2. Perhitungan Biaya Tidak Tetap

Komponen-komponen biaya tidak tetap yang dihitung adalah sebagai berikut:

a. Biaya cuci mobil

b. Biaya kampas rem c. Biaya kampas kopling

d. Biaya Ban

e. Bahan bakar minyak (BBM)

Penggunaan BBM tergantung dari jenis kendaraannya. Penggunaan BBM

f. Biaya retribusi parkir

g. Servis besar

h. Servis kecil

3. Perhitungan Biaya overhead

Tabel 1 Rekapitulasi Biaya Operasional Kendaraan Biaya Keseluruhan

\begin{tabular}{|c|c|c|c|c|c|c|}
\hline \multicolumn{7}{|c|}{ BOK 2016, 2017, \& 2018} \\
\hline Jarak/Tahun & Kegiatan & & Keterangan & Biay & & Keterangan \\
\hline 348972,6667 & Biaya Tetap & 1 & Penyusutan & $\mathrm{Rp}$ & 131,82 & Terlaksana \\
\hline Keberangkatan/Tahun & & 2 & Biaya awak & $\mathrm{Rp}$ & $44.851 .008,00$ & \\
\hline 627 & & & & $\mathrm{Rp}$ & 128,52 & Terlaksana \\
\hline Km/Kebeangkatan & & 3 & Gajih Upah & $\mathrm{Rp}$ & $2.906 .838,00$ & \\
\hline 556,5752259 & & & & $\mathrm{Rp}$ & 2,08 & Terlaksana \\
\hline & & 4 & Biaya Pengelolaan & $\mathrm{Rp}$ & 65,67 & Terlaksana \\
\hline & & 5 & Biaya Admin & $\mathrm{Rp}$ & 21,95 & Terlaksana \\
\hline & Biaya Variabel & 1 & Biaya BBM & $\mathrm{Rp}$ & $1.226,57$ & Terlaksana \\
\hline & & 2 & Biaya Ban & $\mathrm{Rp}$ & 168,55 & Terlaksana \\
\hline & & 3 & Pemeliharaan Kend & & & \\
\hline & & a & Service Kecil & $\mathrm{Rp}$ & 92,57 & Terlaksana \\
\hline & & $b$ & Service Besar & $\mathrm{Rp}$ & 121,21 & Terlaksana \\
\hline & & c & Service Ac & $\mathrm{Rp}$ & 44,92 & Terlaksana \\
\hline & & $d$ & Overhoul Mesin & $\mathrm{Rp}$ & 47,38 & Tidak Terlaksana \\
\hline & & $\mathrm{e}$ & Overhoul Body & $\mathrm{Rp}$ & 4,30 & Tidak Terlaksana \\
\hline & & $f$ & Biaya Cuci Bus & $\mathrm{Rp}$ & 1,96 & Terlaksana \\
\hline & & $\mathrm{h}$ & Biaya Restribusi & $\mathrm{Rp}$ & 22,22 & Terlaksana \\
\hline & BOK & & & $\mathrm{Rp}$ & $2.028,04$ & Per Km-Tahun-Kend \\
\hline & BOK & & & $\mathrm{Rp}$ & 707.731.671,75 & Tahun \\
\hline & BOK & & & $\mathrm{Rp}$ & $1.128 .758,65$ & Keberangkatan \\
\hline
\end{tabular}


Analisa Biaya Operasional Kendaraan ..., Muhammad Gemilang P.U. ${ }^{(1)}$, Nirwana Puspasari ${ }^{(2)}$

\begin{tabular}{|c|c|c|c|}
\hline \multicolumn{4}{|c|}{ BIAYA OPERASIONAL KENDARAAN 3 TAHUN TERAKHIR } \\
\hline \multicolumn{4}{|c|}{$\begin{array}{l}\text { PERHITUNGAN AKHIR } \\
\end{array}$} \\
\hline \multicolumn{4}{|l|}{ Rata-Rata Load Faktor } \\
\hline Load Faktor Total 3 Tahun & & 1,272 & Load Faktor \\
\hline Load Faktor Pertahun & & 0,4240 & Load Faktor \\
\hline \multirow[t]{2}{*}{ Jumlah Penumpang $1 \times$ Trip } & & 11,45 & Penumpang \\
\hline & & 12 & Penumpang \\
\hline \multicolumn{4}{|l|}{ Keutungan 1 x Keberangkatan } \\
\hline Harga 1 Tiket Penumpang & $\mathrm{Rp}$ & 130.000 & \\
\hline Keuntungan $1 \times$ Berangkat & $\mathrm{Rp}$ & 1.560 .000 & \\
\hline \multicolumn{4}{|l|}{ Jumlah Rata-Rata Penumpang } \\
\hline Jumlah Penumpang Total 3 Tahun & & 20.139 & Penumpang \\
\hline Jumlah Penumpang Pertahun & & 6.713 & Penumpang \\
\hline \multicolumn{4}{|l|}{ Jumlah Rata-Rata Keberangkatan } \\
\hline keberangkatan Total 3 Tahun & & 1.882 & Keberangkatan \\
\hline Keberangkatan Pertahun & & 627 & Keberangkatan \\
\hline \multicolumn{4}{|l|}{ Biaya Operasional Kendaraan } \\
\hline Jumlah BOK Pertahun & $\mathrm{Rp}$ & 707.731 .672 & \\
\hline \multicolumn{4}{|l|}{ Hasil Akhir } \\
\hline BOK/Trip & $\mathrm{Rp}$ & 1.128 .159 & Pengeluaran \\
\hline Pendapatan/Trip & $\mathrm{Rp}$ & 1.560 .000 & Pendapatan \\
\hline Keuntungan & $\mathrm{Rp}$ & 431.841 & Keuntungan \\
\hline \multicolumn{4}{|c|}{ SELESAI } \\
\hline
\end{tabular}

Tabel 2. Load Factor (LF) 2016, 2017 dan 2018

\begin{tabular}{|l|l|c|}
\hline No & Tahun & Load Factor \\
\hline 1 & 2016 & 0,627 \\
\hline 2 & 2017 & 0,323 \\
\hline 3 & 2018 & 0,321 \\
\hline Jumlah & 1,272 \\
\hline Rata-Rata & 0,424 \\
\hline
\end{tabular}

Contoh perhitungan rata-rata 3 tahun terakhir:

a. Faktor Load $=\frac{\text { Jumlah Total Penumpang }}{\text { Keberangkatan } \times 27 \text { Kursi }}$

Jumlah Penumpang $2018=6.723$ Penumpang

Keberangkatan(Trip) $2018=627$ Trip

Jumlah Kursi 1 bus $\quad=27$ Kursi

Perhitungan

$=\frac{6.723 \text { Penumpang }}{627 \text { keberangkatan } \times 27 \text { Kursi }}=0,424$

b. Jumlah Penumpang Per-Trip $=L F \times 27$ kursi Perhitungan $=0,424 \times 27=11,45 \sim 12$ Pnp/Trip

c. Keuntungan $1 \times$ Keberangkatan

Harga Tiket $x$ Penumpang Per-Trip

Harga Tiket $\quad=$ Rp 130.000,00

Pendapatan $\quad=$ Rp $130.000,00 \times 12 \mathrm{Pnp}$

$=\operatorname{Rp} 1.560 .000,00$ d. Biaya Operasinal Kendaraan

BOK/Tahun

$=\operatorname{Rp} 707.731 .672$

e. Hasil Akhir

BOK/Trip $=\frac{\text { Rp 707.731.672 }}{627 \text { keberangkatan }}=\operatorname{Rp~1.128.159,-~}$

Keuntungan $=$ Pendapatan - BOK/trip

$=\operatorname{Rp} 1.560 .000-\operatorname{Rp} 1.128 .159=\operatorname{Rp} 431.831,-$

Jum Jumlah Penumpang 3 Tahun $=20.139$ Penumpang

Rata-Rata Penumpang Pertahun $=6.713$

Penumpang/Tahun

Pendapatan = Rata-Rata Penumpang/tahun $\mathrm{x}$ Harga 1 Tiket

$=6.713$ Penumpang/tahun $\times \mathrm{Rp}$ $130.000,00$ 
$=\operatorname{Rp} 872.690 .000,00$

Rumus perhitungan Fare Box Ratio yaitu:

FBR $=\frac{\text { Pendapatan } / \text { Tahun }}{\text { BOK } / \text { Tahun }}$

$$
=\frac{\operatorname{Rp~} 872.690 .000,00}{\operatorname{Rp~} 707.731 .672,00}=1,23
$$

FBR $=1,23$ (Untung)

Jika, FBR $>1$ = Untung

Jika, FBR $<1 \quad=$ Rugi

FBR 1,23> 1 maka perusahaan akan mendapatkan keuntungan.

\section{PENUTUP}

\section{Kesimpulan}

Dari hasil analisis di atas dapat disimpulkan :

a. Besarnya biaya Operasional kendaraan Angkutan umum Bus Damri jurusan Palangka Raya-Pangkalan Bun sebesarRp 707.731.672,00 pertahun, Rp58.977.639,00 perbulan dan $\mathrm{Rp} 1.128 .159,00$ pertrip keberangkatan . Pelaksanaan penelitian ini dilakukan saat kondisi umur bus yang terbilang masih muda yaitu empat tahun, sehingga biaya operasinal kendaraan yang di keluarkan tidak terlalu besar.

b. Jumlah penumpang angkutan umum Bus Damri jurusan Palangka Raya-Pangkalan Bun per Trip sesuai dengan perhitungan Factor Load adalah 12 penumpang per Trip selama tiga tahun terakhir, rata-rata penumpang pertahunnya sebesar 6713 penumpang dan total penumpang selama tiga tahun terakhir sebesar 20.139 penumpang.

c. Besarnya biaya pendapatan angkutan umum bus Damri jurusan Palangka Raya-Pangkalan Bun rata-rata selama satu tahun terakhir sebesar Rp 872.690.000,00, biaya operasional kendaraan rata-rata pertahunnya sebesar $\mathrm{Rp}$ 707.731.672,00 keuntungan pertahunnya sebesar Rp164.958.328,00dan keuntungan perbulannyasebesar Rp13.746.527,00 . Serta Berdasarkan hasil akhir perhitungan Fare Box Ratio (FBR) pertahun nilai perbandingan perusahaan Bus Damri sebesar 1,23 dimana dari persyaratan Fare Box Ratio (FBR) apabila nilai FBR lebih dari 1 maka perusahaan tersebut dapat di nyatakan mendapatkan keuntungan. d. Sesuai dengan pengakuan dari pihak Perusahaan OtobusDamri bahwa harga satu kali keberangkatan saat ini untuk rute Palangka Raya-Pangkalan Bun sebesar Rp 130.000,00,Sedangkan, berdasarkan dari hasil perhitungan Analisa Biaya Tiket Perusahaan dengan harga tiket sebesar Rp. 115.969,74,- perusahaan masih mendapatkan keuntungan sebesar $10 \%$ pendapatan.

\section{Saran}

Berdasarkan kesimpulan yang diperoleh dari hasil penelitian baik kepada pikah pemilik perusahaan serta dari konsumen pemakai jasa angkutan dilapangan, maka dapat diberikan beberapa saran sebagai berikut:

1. Mengingat persaingan dalam moda transportasi kendaraan angkutan Bus tergolong ketat, maka disarankan kepada pihak perusahaan otobusagar dapatmempertahankan atau bahkan meningkatkanpelayanan terhadap penumpang bus, demi kelangsungan perusahaan otobusyang bergantung pada kepuasan dan antusiasme penumpang.

2. Sebagai bahan studi perbandingan bagi mahasiswa yang mengkaji mengenai topik analisa biaya operasional kendaraan bus angkutan kota jurusan Palangka RayaPangkalan Bun di atas serta sebagai bahan referensi agar dapat dikembangkan sesuai dengan minat dan bakat.

\section{DAFTAR PUSTAKA}

Chahyadi, R. (2006). Analisis sistem tarif penumpang angkutan umum bis maju bersama jurusan PalangarayaMuarateweh. Laporan Tugas Akhir. S-1 Fakultas Teknik Sipil Universitas Muhammadiyah Palangkaraya.

Direktorat Jenderal Perhubungan Darat, (2001), Keputusan Direktur Jenderal Perbuhungan Darat Nomor. SK.653/AJ.202.DRJD/2001 Tentang Petunjuk Teknis Penyelenggaraan Angkutan Sewa, Departemen Perhubungan Republik Indonesia. Jakarta.

Murbaningsih, A. (2018). Peraturan Presiden RI No. 16 Tahun 2018 Tentang Pengadaan 
Analisa Biaya Operasional Kendaraan ..., Muhammad Gemilang P.U. ${ }^{(1)}$, Nirwana Puspasari ${ }^{(2)}$

Barang/Jasa Pemerintah. Lembaran Negara RI Tahun.

Nasution, M. N. (2004) "Manajemen

Transportasi". CV. Ghalia Indonesia. Jakarta.

Nasional, P. R. U. J., \& Jalan Provinsi Jilid II, M. S. (1995). Departemen Pekerjaan Umum Direktorat Jendral Bina Marga. Jakarta: Departemen Pekerjaan Umum.

Rahman, R. (2012). "Analisa Biaya Operasi Kendaraan (Bok) Angkutan Umum Antar Kota dalam Propinsi Rute PaluPoso." Jurnal Rekayasa dan Manajemen Transportasi 2.1 (2012).
Warta. (2006). Analisis sistem tarif penumpang angkutan umum bis maju bersama jurusan Palangaraya-Muarateweh. Laporan Tugas Akhir. S-1 Fakultas Teknik Sipil Universitas Muhammadiyah Palangkaraya.

Wulandari, Fitri. (2016) Kajian jasa travel jurusan Palangka Raya - Sampit di tinjau dari biaya operasional kendaraan penumpang. Laporan Tugas Akhir. S-1 Fakultas Teknik Sipil Universitas Muhammadiyah Palangkaraya. 